\title{
A EDUCACÃO INDÍGENA E UMA LEITURA SEMIÓTICA DAS PRÁTICAS CULTURAIS
}

\author{
THE INDIGENOUS EDUCATION AND A SEMIOTIC READING OF CULTURAL \\ PRACTICES
LA EDUCACIÓN INDÍGENA Y UNA LECTURA SEMIÓTICA DE LAS PRÁCTICAS CULTURALES

Edivaldo José Bortoleto* ejbortol@unochapeco.edu.br

REVISTA PEDAGÓGICA

Revista do Programa de Pós-graduação em Educação da Unochapecó | ISSN 1984-1566 Universidade Comunitária da Região de Chapecó | Chapecó-SC, Brasil Como referenciar este artigo: BORTOLETO, E. J. A educação indígena e uma leitura semiótica das práticas culturais. Revista Pedagógica, Chapecó, v. 17, n. 34, p. 133-147, jan/abr.2015.

RESUMO: O Continente Americano é um Continente Absconditus, ou seja, o nome mais encobre que revela e, a América Latina Caribenha, em especial, é um "cadinho" de onde emergem as mais complexas etnias indígenas, aliás, estas não podem ser compreendidas sem a presença da cultura europeia, sem a cultura africana e sem as demais culturas. Portanto, o Continente Latino Americano é o exemplo máximo de culturas velozes que se intercruzam e se transculturalizam-se. A Literatura, portanto, tem sido a forma de apreensão desta forma mentis deste Continente. José María Arguedas, em sua obra, de 1958, Os Rios Profundos, partindo do exemplo do Peru, aproxima a cultura quéchua e a cultura oficial em um intercruzamento semiótico que implica todas as linguagens dos sentidos - linguagens não verbais - e a linguagem verbal. Assim, por meio da obra do peruano Arguedas, pretende-se formular uma leitura semiótica das práticas culturais e pedagógicas no âmbito da Educação Indígena e construir, mais que um paradigma, um sintagma, no sentido de operar a apreensão e compreensão dinâmica - semioticamente falando destes rios profundos que nutrem e dão a fundura deste Continente Absconditus e, esteticamente falando, o Continente, por excelência, Barroco.

PALAVRAS-CHAVE: Literatura Latino Americana. Semiótica e Linguagem. Estética Barroca. Práticas e Pedagogias Indígenas.

ABSTRACT: The American continent is a Continent Absconditus, that is, the name covers most than reveals and the Caribbean Latin America, in particular, is a melting pot from which emerges the more complex indigenous groups that, by the way, can not be understood without the presence of European culture, without African culture and no other cultures. Therefore, the Latin American continent is the example of fast cultures that intersect and transculturalizing itself Literature, therefore, has been the way of learning this forma mentis of this continent. José María Arguedas in his work 1958, The Rivers Deep, starting from the example of Peru, approaches the Quechua culture and the official culture in a semiotic intercrossing that implies all languages of the senses - not verbal languages - and the verbal language. So, through the Peruvian Arguedas's work, it is intended to formulate a semiotic reading of cultural and pedagogical practices in the context of Indigenous Education and build, more than a paradigm, a combination of words, in order to operate the learning and dynamic understanding - semiotically speaking - about these deep rivers that feed and give depth this Continent Absconditus and, aesthetically speaking, the continent, par excellence, Baroque.

KEYWORDS: Latin American Literature. Semiotics and Language. Baroque aesthetics. Indigenous practices and pedagogies.

RESUMEN: El Continente Americano es un Continente Abscondictus, o sea, el nombre más encubre que revela, y la América Latina Caribeña en especial, es un rincón de donde emergen las más complejas etnias indígenas, además de que estas no pueden ser comprendidas sin la presencia de la cultura europea, sin la cultura africana y sin las demás culturas. Por lo tanto, el Continente Latino Americano es el ejemplo máximo de culturas veloces que se entrecruzan y generan el transculturalismo. Así que la literatura ha sido la forma de aprensión de este modo mentis que configura el continente. José María Arguedas en su obra de 1958 - Los Ríos Profundos - partiendo del ejemplo del Perú, aproxima la cultura quechua y la cultura oficial en un entrecruzamiento semiótico que implica todos los lenguajes de los sentidos - el lenguaje no verbal y el lenguaje verbal. De esta forma, mediante la obra del peruano Arguedas, se desea formular una lectura semiótica de las prácticas culturales y pedagógicas en el ámbito de la Educación Indígena y construir, más que un paradigma, un sintagma, en el sentido de operar la aprensión y comprensión dinámica - semióticamente hablando - de estos ríos profundos que nutren y forman la hondura de este continente Absconditus y, estéticamente hablando, el Continente por excelencia, Barroco.

PALABRAS CLAVE: Literatura Latino Americana. Semiótica y Lenguaje. Estética Barroca. Prácticas y Pedagogías Indígenas. 
* Doutor em Comunicação e Semiótica pela Pontifícia Universidade Católica de São Paulo (2003) e Doutor em Educação pela Universidade Metodista de Piracicaba (2010). Professor do Programa de Pós-Graduação Stricto Sensu em Educação da UNOCHAPECÓ.
Tupi, or not tupi that is the question. No Matriarcado de Pindorama.

Oswald de Andrade.Manifesto Antropófago (1978).

Quando o português chegou Debaixo duma bruta chuva

Vestiu o índio

Que pena!

Fosse uma manhã de sol

O índio tinha despido

O português.

Oswald de Andrade.

Um Aspecto Antropofágico da Cultura

Brasileira: O Homem Cordial (1978)

Para Dom Pedro Casaldáliga, profeta das gentes indígenas em Nuestra Madre América

\section{ENTRANDO NOS RIOS PROFUNDOS...}

A questão indígena torna-se, mais do que nunca, uma questão fulcral. Hoje, no século XXI, em número reduzido, o índio não tem o seu espaço demarcado e é assassinado no contexto de um estado de direito. No entanto, importa questionar não só a questão indígena, também a questão negra, a dos africanos que vieram ao Novo Mundo. Se no Brasil, em que pese a resoluuasil, em que pese a resoluão negra, a dos africassa pela miscigenasil, a questsil, em que pese a resoluão negra, a dos africassa pela ieram ao Novo Mundo. ices i Já nos EUA, como resolução dada ao encontro das etnias passa pela segregação, negros são assassinados pelo sistema policial do império que exporta em nome da guerra o seu modelo e valor de democracia ao mundo todo, principalmente, ao mundo muçulmano. Mas, também, a questão do branco se apresenta como uma questão, pois, ainda a estrutura do mundo americano é a europeia. Neste Continente Absconditus, portanto, índios, brancos e negros inaugurarão uma saga das mais difíceis de ser lida.

Assim, nossa história tem a ver com coisas de índios, de negros e de brancos, os quais -, no encontro e na mistura das etnias - construíram a forma mais elevada de estética, no caso latino-americano-caribenho, a barroca, e a forma mais cruenta e tensa de violência de históricas vítimas que somam 115 milhões de indígenas que tão somente no Brasil, sofreram o primeiro holocausto da história da conquista eurocêntrica ocidental.

No Continente Americano enquanto um todo e em sua dimensão maior e, no interior das inúmeras regiões, podemos fazer a experiência e, ao mesmo tempo, o reconhecimento daquilo que Gilberto Freyre irá denominar de o 
continentalismo com o regionalismo. Do universalismo com o localismo. Portanto, da história com a geografia. (FREYRE, 2003: 48). Desta maneira, Gilberto Freyre assim diz:

[...] como um grupo de ilhotas, plásticas em sua maioria, que motivos ou necessidades de natureza igualmente sociológica ou econômica foram solidificando ou agrupando em ilhas maiores ou menores por meio de confederações como a anglo-norte-americana, ou de reinos e depois impérios como o luso-brasileiro, ou repúblicas como as da América Espanhola. De modo que dentro de nossa configuração continental permanece a diversidade sociológica de ilhas que ainda somos.

Para Freyre (2003), o Continente Americano - em sua altura, largura e extensão - é "[...] um arquipélago sociológico de proporções continentais”. E isso supõe a aproximação tanto da história social quanto da geografia física. Por outro lado, a evolução e o desenvolvimento do Continente Americano deu-se muito mais por base provinciana ou regional que por base continental. Ora, considerar o Continente enquanto um arquipélago ou um conjunto de ilhotas, supõe, sem perder a dimensão continental em sua totalidade, olhar para a singularidade de cada região, de cada província, de cada recôndito, para justamente, não cair na homogeneidade desse Continente Abscondistus. Uma noção de uma América lida sobre a perspectiva de um Pan-Americanismo é problemática, pois pode mais do que revelar, esconder, mais que explicitar, ocultar, principalmente sobre o manto de lógicas políticas e de lógicas econômicas. Outrossim, Freyre (2003, p. 49) comenta que a palavra Pan-Americanismo se desenvolveu

[...] como uma espécie de glorificação da ideia de massa ou totalidade americana, que é sem dúvida alguma uma força que deve ser aproveitada pelos estadistas americanos, mas pela qual não devemos nos deixar dominar como por um gigante apenas forte. É um americanismo de quantidade. Nas ilhas, nas províncias, nas regiões se esquece o que tem de bom do ponto de vista da qualidade.

Entretanto, diferentemente de falar-se em Pan-Americanismo, quero falar, justamente, em Madre América e Nuestra América. Segundo Martí, o primeiro nome implica compreender: "Madre América, allí encontramos hermanos! Madre América, allí tienes hijos! (1992, p. 427). Já sobre o conceito de Nuestra América, assim o explica:

Lo que quede de aldea en América há de despertar. Estos tiempos no son para acostarse con el pañuelo a la cabeza, sino con las armas de almohada, como los varones de Juan 
${ }^{1}$ Evangelho de Lucas 5, 4 (BÍBLIA DE JERUSALÉM, 2004).

\footnotetext{
${ }^{2}$ Bella Jozef, em História da Literatura Hispano-Americana, define o fenômeno de transculturação. "O estudo dos fenômenos de transculturação que se produziram depois da conquista são capitais. Esses fenômenos constituem em aspecto primordial de uma história especificamente americana. Os contatos euro-indígenas e as contribuições africanas estabelecem-se durante grande parte do século XVI. Os elementos que irão evoluir em conjunto durante o período colonial e o nacional já existem após 1500" (JOZEF, 2005, p. 14).
}

de Castellanos: las armas del juicio, que vencen a las otras. Trincheras de ideas, valen más que trincheras de piedras. (MARTÍ, 1992, p. 480).

Madre América e Nuestra América, lugares de irmãos e de filhos e de ideias, portanto, lugares onde "pensar es servir" (MARTÍ, 1992, p. 487).

\section{FAZE-TE AO LARGO; LANÇAI VOSSAS REDES PARA A PESCA! ${ }^{1}$}

Assim, parece-me que a primeira forma de trincheiras de ideias que este Novo Mundo viu emergir foi a da Literatura. Sem dúvida alguma, a Filosofia e a Teologia estiveram e constituíram o primeiro substrato de ideias que desenharam e ainda estão a desenhar o modo e o jeito desse Continente "se dizer". Sobre esta questão, falarei mais a frente. No entanto, nessa primeira forma de ideias que se revela e se manifesta na Literatura, faz-se nossa primeira estética tanto em forma de prosa quanto em forma de verso. E essa Literatura que vai se formando, que vai se desenhando, agora, não mais em solo europeu, é uma Literatura que vai se fazendo pelo fenômeno de transculturação. ${ }^{2}$ Jozef (2005, p. 13) é incisiva quando, ao falar da Literatura de Transculturação, reconhece a contribuição indígena em toda sua complexidade enquanto substrato sociocultural que deve ser considerado:

Depois dos estudos modernos de etnologia, é impossível negar-se a influência das civilizações que viviam na América antes da chegada de Colombo. Possuíam algumas, como as do México e do Peru, um tipo de cultura muito complexa, com cidades construídas e estratificação dos grupos sociais. Embora a estrutura da civilização americana seja européia (sic), algumas características são autóctones. As armas que destruíram essas culturas não impediram que muito ficasse no substrato. $\mathrm{E}$ quando um Vallejo ou Neruda pulsam a lira indo-hispana, não se trata de mera inspiração literária ou traço lírico. É o substrato sociocultural que deve ser levado em conta.

Conforme já desenvolvido por mim, em outro ensaio inspirado no pensamento de Enrique Dussel,

[...] o mundo dos maia-astecas, dos incas, dos chibchas e os índios da América do Norte e os da América do Sul era constituído por um complexo lingüístico (sic) religioso, pensando como um sistema vivo e dinâmico relacionado com os ritmos dos astros, das águas, da vegetação, dos animais, da existência humana, formando, assim, um lar cósmico demoradamente e penosamente construído e criado. (BORTOLETO, 2000, p. 82). 
Esse substrato de que fala Josef (2005), constitutivo deste lar cósmico dinâmico que nossas primeiras gentes construíram demoradamente e penosamente, foi o que ficou sob forma de "rios profundos". Para já se ir trazendo as primeiras figuras da obra de Arguedas (2005, p. 32): "De tarde chegamos ao pico das cordilheiras que cercam o Apurímac. 'Deus que fala' é o significado do nome desse rio. Apurímac mayu! Apurímac mayu! - repetem as crianças de fala quéchua, com ternura e um pouco de espanto".

Se na dialética da conquista, a estrutura da civilização europeia se impõe na América, o substrato da cultura autóctone corre como rio vivo e profundo. Esta a razão pela qual, real e metaforicamente os rios são decisivos no Continente Americano. Em minha primeira tese de doutorado - América Latina e Caribenha: Comunicação e Alteridade ${ }^{3}$ - trago uma entrevista de João Guimarães Rosa a Günter Lorenz de 1965, retirada da obra de Beth Brait, "Guimarães Rosa. Seleção de textos, notas, estudos biográfico, histórico e crítica e exercícios", na qual Rosa assim revelou:

[...] Em outras palavras, gostaria de ser um crocodilo vivendo no rio Se exercíciosica e exercíciosa razão pela qual, "magister" da metafísica, pois para ele cada rio é um oceano, um mar de sabedoria, mesmo que chegue a ter cem anos de idade. Gostaria de ser um crocodilo porque amo os grandes rios, pois são profundos como a alma de um homem. Na superfície são muito vivazes e claros, mas nas profundezas são tranquilos e escuros como o sofrimento dos homens. Amo ainda uma coisa dos nossos grandes rios: sua eternidade. Sim, rio ele cada rio é um oceano, um mar de sabedori. (BORTOLETO, 2003, p. 28-29).

“Apurímac mayu! Apurímac mayu! - repetem as crianças de fala quéchua, com ternura e um pouco de espanto". (ARGUEDAS, 2005:32). Mas, na dialética da conquista, o outro que é conquistado. Não é aniquilado em absoluto, pois ele vive nas funduras subterrâneas das estruturas socioculturais. Esse processo ocorre com o negro também neste Continente Absconditus. Assim, este Continente Absconditus, este continens terra (esta terra firme) - arquipélagos de ilhotas física e culturalmente falando; afinal, aqui, história social e geografia física se conciliam, como diz Freyre (2003) - será o cenário, o palco da história onde o Velho Mundo irá se impor com toda sua maldade. Esse Velho Mundo que, conforme Hegel, Napoleão teria dito "Cette vieille Europe m'ennuie": "[...] debe apartarse del suelo en que, hasta hoy, se he desarrollado la histarro universal. Lo que hasta ahora acontece aqui no es mes mLo que hasta ahora acontece aqui no es mMundo irá se" (HEGEL, 1989, p. 177).

Frei Bartolomé de Las Casas (1474-1566), desde uma analítica tomasiana por primeiro irá dizer esse mundo, esse 
paraíso que foi destruído, pois “[...] no índio que morre prematura e injustamente vê o Cristo e, por isso, sua reflexão terá um acentuado enfoque cristológico" (GUTIÉRREZ, 1995, p. 21). Nossa primeira exegese bíblica, cristologicamente falando, portanto. Sua Brevísima relación de la destrucción de las índias, primeira fotografia e radiografia do que foi e do que significou a maldade imputada às primeiras gentes deste continens terra. Em La historia de las índias e em sua famosa Apologia, encontram-se as primeiras trincheiras de ideias - portanto, em uma perspectiva profética - do diálogo com o pensamento do centro, do Velho Mundo. Aqui, Las Casas trava um debate com Juan Ginés de Sepúlveda (1490-1573) sobre a questão da Jure Belli. E essa discussão - a da Guerra Justa já estava presente em Francisco de Vitória (1492-1516) em "Os Índios e o Direito da Guerra (De Indis et de Jure Belli Relecationes)" (VITÓRIA, 2006). Assim, ao longo e ao largo, das doze $\mathrm{Ob}$ jeções (Sepúlveda) e Réplicas (Las Casas), encontrar-se-ão a expressão anima e alma. Isto porque, se está num contexto onde há uma discussão filosófico-teológica que se dá em torno da questão do índio ser gente ou não (BORTOLETO, 2003, p. 104).

Com José Martí (1853-1895), o Apóstol de la Libertad, pode-se, assim afirmar, nasceu a ideia de América (de Madre América, de Nuestra América). Será com o Apóstolo da Liberdade que nascerá, segundo Krauze em "Os Redentores: Ideias e Poder na América Latina”, a história do moderno ideário revolucionário na América Latina (KRAUZE, 2011). Com Madre América (1889) e Nuestra América (1891), nasceu a pedra fundamental do latino-americanismo no século XX (KRAUZE, 2011, p. 30). Em Madre América a descrição do que o conquistador fez com "a gente índia" neste continens firme segue-se na mesma discrição que Frei Bartolomé outrora fizera em suas obras, sempre em perspectiva profética. Neste sentido, as Obras Completas de Martí constituem-se no marco fundacional da América no Século XX. Em Madre América, é possivel comprender a ótica de Martí:

Por entre las divisiones y celos de la gente índia adelanta en América el consquistador; por entre aztecas y taxcaltecas llega Cortés a la canoa de Guauhtémoc; por entre quichés y zutujiles vence Alvarado en Guatemala; por entre tunjas y bogotáes adelanta Quesada en Colômbia; por entre los de Atahualpa y los de Huáscar pasa Pizarro en el Peru: en el pecho del último indio valeroso clavan, a la luz de los templos incendiados, el estandarte rojo del Santo Ofício [...]. (MARTÍ, 1992, p. 423).

Ernesto na viagem de trem com seu pai - em Os Rios Profundos - passa ao cume do Sacsay-huaman (que quer 
dizer "Águia repleta" em quéchua). Ele, não mais de trem, mas em cavalos, via Cusco. "Enquanto trotávamos na planície imensa, eu via Cusco" - narra Ernesto.

As cúpulas dos templos à luz do sol, a longa praça onde as árvores não podiam crescer. Como é que os eucaliptos tinham se desenvolvido, então, nas encostas do Sacsyhuaman? Os senhores avarentos talvez tivessem envenenado, com seu hálito, a terra da cidade. Moravam antigos solares desde os tempos da conquista. Lembrei-me da imagem da pequena verbena-cidrada da casa do Velho. (ARGUEDAS, 2005, p. 31).

Com seus hálitos e seus sopros, os senhores avarentos e conquistadores foram levando à ruína a cultura dinâmica e complexa deste continens firme. Hegel defende que o sopro do espírito (o seu hálito) levará à ruína o Novo Mundo. Segundo o autor, com a conquista do país,

[...]se]ísq la ruína de su cultura, de la cual conservamos noticias; pero se reducen a hacernos saber que se trataba de una cultura natural, que había de perecer tan pronto como el espíritu se acercara a ella. América se há revelado siempre y sigue revelandose impotente en lo físico como en lo espritual. Los indígenas, desde el desembarco de los europeus, han ido pereciendo al soplo de la actividad europea. (HEGEL, 1989, p. 170-171, grifo do autor).

No Peru de José María Arguedas e de Gustavo Gutiérrez, José Carlos Mariátegui (1894-1930) formulará a primeira leitura marxiana genuinamente latino-america-caribenha. Em "Sete Ensaios de Interpretação da Realidade Peruana”, Mariátegui subsume a questão indígena e o índio como o sujeito fundamental e decisivo no processo da transformação e da revolução latino-americana-caribenha. Assim, para Mariátegui (2010, p. 57), "[...] a suposição de que o problema indígena é um problema étnico se nutre do repertório mais envelhecido das ideias imperialistas. $\mathrm{O}$ conceito de raças inferiores serviu ao Ocidente branco para sua obra de expansão e conquista". Fornet-Betancourt em "O Marxismo na América Latina", diz, concordando com Michael Löwy que:

José Carlos Mariátegui não é somente o primeiro grande pensador marxista latino-americano, senão também uma figura de extraordinária atualidade política e cultural. A renovação da teoria marxista na América Latina tem sua condição no redescobrimento e na retomada de sua mensagem espiritual revolucionária e herética. (ORNET-BETANCOURT, 1995, p. 114). 
${ }^{4}$ As notas entre parêntesis são de autoria da tradutora de "Os Rios Profundos (Los ríos profundos)” Josely Vianna Baptista.
Assim, Mariátegui (2010) está no mesmo eixo de perspectiva profética de que Gutiérrez (1995) disse de Frei Bartolomé de Las Casas. O próprio Mariátegui também reconhece em Las Casas a voz vibrante e defensora dos indígenas no continens terra. Quando Maríategui estabelece a diferença do vice-reinado e da república na história do continente latino-americano-caribenho, fazendo a crítica de que a república não levou em questão, no tocante ao problema da terra (e isto ainda é atual, principalmente na realidade Brasileira), a questão do índio, também é capaz de reconhecer que, no período do vice-reinado, a voz de Las Casas se levanta frente à miséria e ao esmagamento do indígena. Outrossim, Mariátegui argumenta que:

$\mathrm{O}$ vice-reinado aparece menos culpado que a república. Corresponde ao vice-reinado, originalmente, toda a responsabilidade pela miséria e o esmagamento dos índios. Mas, nesse tempo inquisitorial, uma grande voz cristã, a do frei Bartolomeu de Las Casas, defendeu de forma vibrante os índios contra os métodos brutais dos colonizadores. Não houve na república um defensor tão eficaz e determinado da raça aborígine. (MARIÁTEGUI, 2010, p. 63).

Na narrativa de Ernesto, na ocasião em que ele e seu pai se encontram na Fazenda, há a discrição de um encontro de fazendeiros com índios em dia festivo:

Os fazendeiros dos pequenos povoados contribuem com grandes vasilhas de chicha (bebida fermentada, geralmente feita de milho) e caldeirão de picantes (pratos crioulos que têm como ingrediente básico o pimentão) para os trabalhos comunitários. Nas festas, vão para as ruas e praças, cantar huaynos (canção e dança popular de origem inca) em coro e dançar. Caminham diariamente, com polainas velhas, roupas de bombazina ou cassineta, e um cachecol de vicunha ou de alpaca no pescoço. Vêm em cavalos de paso (cavalos adestrados e garbosos que bracejam ritmadamente ao trotar), usam esporas de bronze e, sempre, sobre a sela, um pelego de couro de ovelha. Vigiam os índios face a face e, quando estes querem mais do que comumente se pensa que é o justo, eles mesmo partem-lhes a cara ou os levam aos pontapés até a prisão [...]. (ARGUEDAS, 2005, p. 54). ${ }^{4}$

A semiótica de ambiente, da culinária, da dança, dos cantos, das vestimentas das pessoas e dos animais se misturam com os signos das diferenças que justificam a opressão, portanto, na dialética da conquista, os signos abundam e se proliferam.

Assim, desde Frei Bartolomé de Las Casas, passando por José Martí, até José Mariátegui, na dialética da conquista há uma semiótica da violência constituindo os 
${ }^{5}$ Dentre os elementos aqui elencados, alguns, foram buscados na obra de Connor (1993).

\footnotetext{
${ }^{6}$ Evangelho de João 7,38 . A passagem citada em João em sua forma completa, referenciando-se sempre na Antiga Aliança é assim: "Se alguém tem sede, venha a mim/e beberá, aquele que crê em mim!" Conforme a palavra da Escritura: De seu seio, jorrarão rios de água viva (BÍBLIA DE JERUSALÉM, 2004).
}

sofrimentos dos rios profundos, estes, constituidores do substrato sociocultural de Nuestra Madre América formada por arquipélagos de ilhotas. Se há uma violência que se apresenta na superfície vivaz e clara dos rios, há outra que se apresenta nas profundezas tranquilas e escuras, e como diz João Guimarães Rosa, são como que o sofrimento dos homens. Esse sofrimento, portanto, é o sofrimento capturado pela Literatura. É ela que apreende, à maneira de um "magister" da metafísica, as funduras mais fundas deste Continente Absconditus que nasceu já moderno em 1492.

Esse sofrimento, portanto, está na base da estética barroca latino americana que vai se configurando nas inúmeras formas de linguagens como a Literatura - tanto na prosa quanto na poética -, na arquitetura, na escultura, na pintura, na música, na forma da organização das cidades nos espaços da Latino América Caribenha, e assim, na irregularidade, na sinuosidade, na anarquia, na ausência, na dispersão, no exagero, na espontaneidade, no desejo, constituindo-se muito mais em um sintagma que em um paradigma. ${ }^{5}$

Bortoleto e Meneghetti (2014) sinalizam sobre esse processo quando afirmam que "nestes primeiros trezentos anos, uma estética foi sendo tecida", saída do resultado do encontro e das confluências das várias etnias: as autóctones, a europeia, advinda principalmente da Península Ibérica, espanhóis e portugueses, trazendo, também, toda cultura moura para cá, bem como as africanas. Desta mistura tensionada e marcada pela força da violência, emerge uma estética, a Estética Barroca, que constituir-se-á no contradiscurso à tradição europeia, em tudo diferente já do Barroco europeu apaziguador e consoante ao poder absolutista. Das mãos, então, de Frei Bartolomé de Las Casas (1474-1566), de Sor Juana Inês de La Cruz (1648-1695), de Antônio Vieira (1608-1697), de Gregório de Mattos (1636-1696), de Antonio Francisco Lisboa, o Aleijadinho (1738-1814) e de José Maurício Nunes García (1767-1830), para citar tão somente alguns, encontrar-se-á, desde a prosa, a poesia, a pintura, a arquitetura, a música e os elementos sígnicos os mais perenes constitutivos da civilização ainda em processo que é o Continente Absconditus Latino-Americano Caribenho. Toda a Estética Barroca será potencializada em uma forte Teoria Neobarroca saída das mãos de José Lezama Lima (19101976), de Alejo Carpentier (1904-1980), de Severo Sarduy (1937-1993), de Haroldo de Campos (1929- 2003), de Samira Chalhub, servindo como nosso contradiscurso, principalmente à acumulação do mercado capitalista e auxiliando na formulação do real maravilhoso latino-americano caribenho (BORTOLETO; MENEGHETTI, 2014, p. 33).

\section{DO SEU SEIO, JORRARÃo RIOS DE ÁGUA VIVA $^{6}$}

O rio, o temido Pachachaca tem a ver com a alma de Ernesto e, esta, a alma de Ernesto, tem a ver com o temido 
7 "Do Magistério e da Educação: A Primeira Filosofia na Colônia e a Segunda Escolástica - Séculos XVI e XVII”. Tese de Doutorado defendida no Programa de Educação na Universidade Metodista de Piracicaba em Agosto de 2010, sob a orientação do Prof. Dr. José Maria de Paiva. rio Pachachaca. Sobre o rio, havia uma ponte construída pelos espanhóis; e Ernesto não sabia se amava mais a ponte ou o rio: "Eu não sabia se amava mais a ponte ou o rio. Mas ambos desanuviavam minha alma, inundavam-na de força e de sonhos heróicos (sic). Apagavam-se de minha mente todas as imagens chorosas, as dúvidas e as lembranças ruins" (ARGUEDAS, 2005, p. 87).

O Pachachaca, o rio temido, "[..] aparece num ângulo liso, pela base de um precipício onde crescem apenas trepadeiras de flor azul. Neste precipício costumam descansar os grandes papagaios viajantes; prendem-se nas trepadeiras e gritam lá das alturas" (ARGUEDAS, 2005, p. 86). E Ernesto, em sua solidão, quando se sentia sozinho assim dizia de si mesmo: "Durante muitos dias depois eu me sentia sozinho, firmemente isolado. Devia ser como o grande rio: cruzar a terra, cortar as rochas; passar, incessante e tranquilo, entre os bosques e as montanhas; e entrar no mar, acompanhado por um grande bando de aves que cantariam nas alturas" (ARGUEDAS, 2005, p. 87). A semiótica do rio temido porque profundo e a semiótica da alma solitária porque profunda se enlaçam em uma inter-semiótica. $\mathrm{O}$ rio e a alma. $\mathrm{O}$ Pachachaca e Ernesto. A Natureza e a Cultura.

O fundo dos rios profundos e o fundo da alma profunda constituem-se rios profundos desta Nuestra Madre América, deste Continente Absconditus. Destes seios de Nuestra Madre América de onde jorram rios de água viva. Este é o transfundo mais fundo da contribuição indígena e, depois, o fundo do pensamento ibérico que foi se misturando com o transfundo mais fundo da cultura indígena. Dizendo d'outra maneira, a Segunda Escolástica Ibérica, Lusa e Hispânica constituirão, juntamente com a cultura indígena nossa modernidade. Em uma segunda tese de doutorado desenvolvi esta questão. ${ }^{7}$ Logo, na Segunda Escolástica

[...] está nossa modernidade, aquela que se constitui no e a partir do Novo Mundo. Nossa modernidade não está, portanto, na tradição do Cogito, ergo sum de Descartes que perpassará a tradição da Ilustração até Hegel e depois dele. Nossa modernidade está na Escolástica. René Descartes é uma via de acesso à modernidade, aquela que se desenvolverá, no que Edith Stein chamou de Filosofia Moderna. Mas a modernidade tem outras vias de acesso. A via da Península Ibérica será a da Escolástica, e aí, encontrar-se-á o que a filósofa judia chamará de Filosofia Escolástica Católica. Esta é a Filosofia que nos chegou pelas mãos da Espanha constituindo o lado hispânico do Novo Mundo; a mesma Filosofia Escolástica nos chegou pelas mãos de Portugal, no lado luso, assumindo aqui a miscigenação cultural presente nas relações com a Colônia. (BORTOLETO, 2010, p. 17-18).

Tanto o percurso da Filosofia Escolástica Hispânica quanto o da Lusa seguirão processos distintos em ambas 
Américas. Isso por quê? Justamente porque a América Hispânica fundou a Universidade desde os primeiros momentos da conquista; por conseguinte, a história da Universidade na América Hispânica se confunde com a própria história da América Hispânica e o desenvolvimento da Escolástica. Já na América Lusa, a invenção da Universidade é algo recente. Dar-se-á tão somente no século XX. Mas, o fundamental, é reter que a nossa modernidade está já na Anti-Modernidade ibérica. Paz (1995, p. 76) salienta que:

(...) Los norteamericanos nacieron con la Reforma y la Ilusración, es dicir, con el mundo moderno; nosostros, con la Contrarreforma y la neoescolástica, es decir, contra el mundo moderno. No tuvimos ni revolución intelectual ni revolución democrática de la burguesia. El fundamento filosófico de la monarquía católica y absoluta fue el pensamiento de Suarez y sus discípulos de la Compañia de Jesús. Estos teólogos renovaron, con gênio, al tomismo y lo conviertieron en una fortaleza filosófica. El historiador Richard Morse há mostrado con penetración que la función del neotomismo fue doble: por una parte, a veces de un modo explícito $y$ otras implícito, fue la base ideológica de sustentación del imponente edifício político, jurídico y econômico que llamamos Império español; por outro, fue la escuela de nuestra clase intelectual y modeló sus hábitos y sus actitudes. En este sentido - no como filosofía sino como actitud mental - su influencia aún pervive entre los intelectuais de América Latina. (PAZ, 1995: 76).

Desta maneira, no subterrâneo do solo deste Continente Absconditus, em seus rios profundos, se encontram o manancial de cujo seio corre os rios de água viva que irão nutrir a formação da Estética Barroca, a formação do pensamento latino americano em suas formas filosófica - a Filosofia da Libertação - e teológica - a Teologia da Libertação. Estas três formas de pensamento, a Estética, a Filosófica e a Teológica só podem ser, tão somente, compreendidas como expressão originária dos nossos rios profundos deste arquipélago de ilhotas que constituem este dinâmico continente, principalmente, a América Latina Caribenha. Três formas de expressão que põem em questão as formas de exploração e de exclusão, portanto, formas de dizer da opressão e dominação em que se encontra este ainda Novo Mundo. Desde o tema do belo, da razão e da fé, estas formas de expressão, apontam já, como um contradiscurso, o processo de opressão/dominação/libertação.

Frente a um mundo que acumula, a Estética Barroca esbanja; frente a um mundo que oprime e domina, a Filosofia da Libertação pela razão e a Teologia da Libertação pela fé se constituirão em formas críticas, pois operam 
${ }^{8}$ Este romance me caiu às mãos por sugestão de Frei Betto, frade dominicano, quando de um diálogo consigo sobre as coisas da cultura, da filosofia e da teologia. Em conversa, ele me sinalizou que esta obra de Arguedas exerceu profunda influência em Gustavo Gutiérrez e em sua formulação da Teologia da Libertação. Daí a razão de, neste trabalho, explicitar, pelo menos três importantes pensadores peruanos, quais sejam: José Carlos Mariátegui, José María Arguedas e Gustavo Gutiérrez, todos tomados pelos rios profundos da cultura indígena. no sentido, também, de resgatar a riqueza da linguagem e simbologia, do complexo semiótico que é este Continente Absconditus, principalmente das gentes vitimárias de um sistema perverso e não humano. Assmann (1981, p. 80) sinalizou sobre a importância da religião na América Latina Caribenha quando - "[...] dizia um antropólogo - não é simples muletas. Ela é os pés e boa parte da caminhada dos pobres”. Dussel (1984, p. 286), por sua vez, desde a Filosofia da Libertação (mas também da Teologia da Libertação e da História), alerta que:

Nos países latino-americanos, cujos primeiros habitantes atingiram elevadas culturas neolíticas, como no México, na Guatemala e outras nações da América Central, parte da Colômbia, Equador, Peru e Bolívia, ou permaneceram em graus primários de cultura (como no Brasil), o problema do indígena se torna cada dia mais crucial.

Assim, tanto a Literatura em sua forma muito especial, visto que: "[...] la literatura expresa a la sociedad; ao expresarla, la cambia, la contradice o la niega. Al retratarla, la inventa; al inventarla, la revela" (PAZ, 1995, p. 73) - quanto à Filosofia e à Teologia em suas formas proféticas e liberacionistas, estão a fundar uma práxis pedagógica, a qual, principalmente, orienta uma forma de compreensão da educação indígena. Esta supõe, por sua vez, uma leitura semiótica das práticas culturais de cada etnia indígena - sem homogeneizações - em cada ilhota cultural constitutiva deste arquipélago americano, principalmente, o latino-americano-caribenho. Além do mais, na Literatura está a primeira experiência estética do mundo, da realidade das coisas, da existência, do numinoso, das gentes, principalmente das gentes que sofrem nos rios profundos de sua alma e nos rios profundos de seu corpo. No campo filosófico e no campo teológico, não podemos também nos esquecer de que as experiências tanto da razão quanto da fé estão a supor uma experiência estética primeira.

José María Arguedas (1913-1969) 8 escreveu contos e romances. O romance "Los rios profundos", de 1958, retrata a transculturadidade da cultura oficial do Peru e da complexa cultura quéchua (o Peru Oficial e o Peru Profundo), a tensão semiótica expressada na vida das gentes, principalmente do índio em seu cotidiano e explorado pelos brancos. Conhecedor tanto da língua espanhola quanto da língua quéchua, Arguedas irá retratar no conjunto de sua obra "[...] a beleza sombria e violenta dos Andes com profundo lirismo". Revelará, por meio da linguagem, a realidade humana do índio, em toda a sua complexidade, uma vez que investigou, minuciosamente, o folclore quéchua, para evitar o retrato estereotipado do índio. "Descreve os hábitos dos indígenas, sua afeição pelos animais e frustração em face da opressão dos brancos" (JOZEF, 2005, p. 201). 
Ao descrever o harpista tocando uma melodia bem como as estrofes do huayno, Ernesto apreende a tristeza no ritmo lento, no tom e nas palavras na canção do Rio Paraisancos. Ernesto indaga:

\begin{abstract}
Por que nos rios profundos, nesses abismos de rochas, de arbustos e sol, o tom das canções era doce, sendo bravia a correnteza poderosa das águas, tendo os precipícios esse semblante aterrador? Talvez porque nessas rochas, flores pequenas, muito tenras, brincam com o ar, e porque a correnteza estrondosa do grande rio segue entre flores e trepadeiras onde os pássaros são alegres e felizes, mais do que em qualquer outra parte do mundo. $\mathrm{O}$ canto continuou acentuando o lamento nos outros versos [...]. (ARGUEDAS, 2005, p. 233).
\end{abstract}

Na formulação de uma Educação Indígena, a experiência estética, marcada pela experiência da tristeza, mas também da alegria e da felicidade, como afecções primeiras que nos tomam nesta outra parte do mundo, que talvez não seja oriental, nem ocidental, mas sim das funduras vivas, cujas memórias estão a dizer de uma história e de uma geografia - de um tempo e de um espaço que continuam sendo aterradores, visto que representam a experiência fundamental do real maravilhoso. (...) Então, desde este lugar metafísico, porque das funduras dos rios profundos, uma arquitetônica, onde, junto com a pedagógica também esteja uma econômica, uma política, uma religiosa está por ser construída no horizonte onde "Pensar es servir". (MARTÍ, 1992, 487).

\section{REFERÊNCIAS}

ANDRADE, O. de. Obras Completas VI - Do Pau-Brasil à Antropofagia e às Utopias. Manifestos, teses de concursos e ensaios. 2. ed. Rio de Janeiro: Civilização Brasileira, 1978.

ARguedas, J. M. Os Rios Profundos. São Paulo: Companhia das Letras, 2005.

ASSMANN, H. A Teologia da Libertação faz Caminho ao Andar. In: Editora Unimep, 1981

BÍBLIA DE JERUSALÉM. Nova edição, ver. e ampl. 3. ed. São Paulo: Paulus, 2004.

BORTOLETO, E. J. América Latina e Caribenha: Comunicação e Alteridade. 2003. ooof. Tese (Doutorado em Educação) - Programa de Pós-Graduação em Comunicação e Semiótica, Pontifícia Universidade Católica de São Paulo, São Paulo, 2003. 
Do Magistério e da Educação: A Primeira Filosofia na Colônia e a Segunda Escolástica - Séculos XVI e XVII -. Tese de Doutorado. Universidade Metodista de Piracicaba. Piracicaba-SP, 2010.

TERRA BRASILIS: do paraíso de deus(es) e de gentes (in)crédulas ou do lugar d'onde "não existe pecado do lado debaixo do equador". IN: IMPULSO - Revista de Ciências Sociais e Humanas. Volume 12 - 2000 - Número 27.

.; MENEGHETTI, R. G. K. Dos Conceitos de Ciência da Religião e do Ensino Religioso: Diálogos Necessários. NUMEN - Revista de Estudos e Pesquisa da Religião da Universidade Federal de Juiz de Fora, Juiz de Fora, v. 17, n. 1, p. 15-50, 2014.

CONNOR, S. Cultura Pós-Moderna: Introdução às Teorias do Contemporâneo. São Paulo: Edições Loyola, 1993.

DUSSEL, E. D. Caminhos de Libertação Latino-Americana: Reflexões para uma Teologia da Libertação, v. 4. São Paulo: Edições Paulinas, 1984.

FORNET-BETANCOURT, R. O Marxismo na América Latina. São Leopoldo: Editora UNISINOS, 1995.

FREYRE, G. Americanidade e Latinidade da América Latina e Outros Textos Afins. Organização de Edson Nery da Fonseca. Brasília: Editora UNB; São Paulo: Imprensa Oficial do Estado de São Paulo, 2003.

GUTIÉRREZ, G.Em Busca dos Pobres de Jesus Cristo: O Pensamento de Bartolomeu de Las Casas. São Paulo: Paulus, 1995.

HEGEL, G. W. F. Lecciones sobre la filosofía de la historia universal. Madrid: Alianza Editorial, 1989.

JOZEF, B. História da Literatura Hispano-Americana. 4. ed. rev. e ampl. Rio de Janeiro: Editora UFRJ; Francisco Alves Editora, 2005.

KRAUZE, E. Os Redentores: Ideias e Poder na América Latina. São Paulo: Saraiva; Benvirá, 2011.

MARIÁTEGUI, J. C. Sete Ensaios de Interpretação da Realidade Peruana. 2. ed. São Paulo: Expressão Popular: Clacso, 2010.

MARTÍ, J. Obras Escogidas en três tomos. - Tomo II - 1886 - ocatubre 1891. Celección Textos Martianos. La Habana-Cuba: Editorial de Ciencias Sociales, 1992. 
147 A EDUCAÇÃO INDÍGENA E UMA LEITURA SEMIÓTICA DAS PRÁTICAS CULTURAIS

PAZ, O. Ideas y Costumbres I. La Letra y el Cetro. Obras Completas Edición del Autor. México: Fondo de Cultura Econômica, 1995.

VITÓRIA, F. de. Os Índios e o Direito da Guerra (De Indis et de Jure Belli Relectiones). Ijuí: Editora UNIJUÍ, 2006. 